\title{
Arduino based Fire Detection and Alarm System Using Smoke Sensor
}

\author{
May Zaw Tun ${ }^{1}$, Htay Myint ${ }^{2}$ \\ Lecturer $^{12}$ \\ ${ }^{1}$ Natural Science Department, ${ }^{2}$ Department of Engineering Physics \\ ${ }^{1}$ University of Computer Studies (Mandalay), ${ }^{2}$ Technology University (Mandalay) \\ ${ }^{12}$ Mandalay, Mandalay Division \\ Myanmar
}

\begin{abstract}
The fire detection system combines the simultaneous measurements of smoke, carbon monoxide, and carbon dioxide. The security of campus against intruders moving in laboratories, class rooms, staffrooms or washrooms. The fire alarm system consists of Fire detectors (with can be smoke detector, heat, or Infra-Red detectors), control unit and alarm system. A fire detection system is developed based on the simultaneous measurements of temperature and smoke. The fire detection system with the alarm algorithm detected fires that were not alarmed by smoke sensors, and alarmed in shorter times than smoke sensors operating alone. Previous fire detection algorithms used data from sensors for temperature, smoke, and combustion products. The smoke sensor alarms when the analog output signal exceeds or equal the threshold value. The node includes analog sensors to measure smoke, carbon monoxide $(\mathrm{CO})$ and temperature. A fire alarm system should reliably and in a timely way notify building occupants about the presence of fire indicators, such as smoke or high temperatures.
\end{abstract}

Key Words: Arduino UNO, MQ2 Gas Sensor, DH-11 sensor, GSM Module, LCD and Buzzer.

\section{INTRODUCTION}

Fire and Gas detection alarm systems are important tools for safeguarding our residence home, building, office, market, and other places. A well designed fire and gas system is intended to detect and in some cases automatically mitigate fire, flammable gas and toxic gas hazards. Proper placement of detectors is critical in the design of a fire and gas system to ensure that coverage is adequate to detect hazards at their incipient stage, in order to prevent escalation. The rates of increase of these three components are used in the fire alarm algorithm to determine the presence of a fire. The smoke sensor provides a mean to detect smoke and to serve as an early fire warning. Heat detectors are the oldest type of automatic fire detection device [5]. They respond either when the detecting element reaches a predetermined fixed temperature or to a specified rate of temperature change. If a fire should result, systems can be attached to extinguish the fire and protect other areas from the actions of the fire. Generally, the fire detection system and gas detection system is combined into one fire and gas system. A separation that may be made is to have one fire and gas system for the processing areas and another sub-system for the usefulness or office/accommodation areas.

\section{SYSTEM COMPONENTS AND TYPES}

This system is implemented fire and gas detection and alarm. It consists of the following components to integrate the system goal: Arduino UNO [1, 2], GSM module SIM900. Gas sensor MQ-2, Temperature and Humidity sensor DH-11, Buzzer, and the Liquid Crystal Display LCD.

\subsection{Arduino UNO}

Arduino Uno is microcontroller board and based on the Atmel's ATmega328 microcontroller. "Uno" means one in Italian and the uno board is the latest in a series of USB (Universal Serial Bus). The Arduino Uno board has a $16 \mathrm{MHz}$ ceramic resonator, a USB connection, a power jack, an ICSP header, a reset button, 6 analog inputs and 14 digital input/output pins (of which 6 can be used as PWM outputs). The board has $32 \mathrm{~KB}$ flash memory of which $0.5 \mathrm{~KB}$ is used by boot-loader, $2 \mathrm{~KB}$ of SRAM, $1 \mathrm{~KB}$ of EEPROM and $16 \mathrm{MHz}$ clock speed. The Arduino system offers a set of analog and digital pins that can be integrated to many other boards and circuits which absolutely have different functions in a design. Arduino board provides a USB 
serial communication interfaces for loading the codes from computer. To do the codes, Arduino has prepared its own software called integrated development environment (IDE) which completely supports $\mathrm{C}$ and $\mathrm{C}++$ programming languages [1, 2].
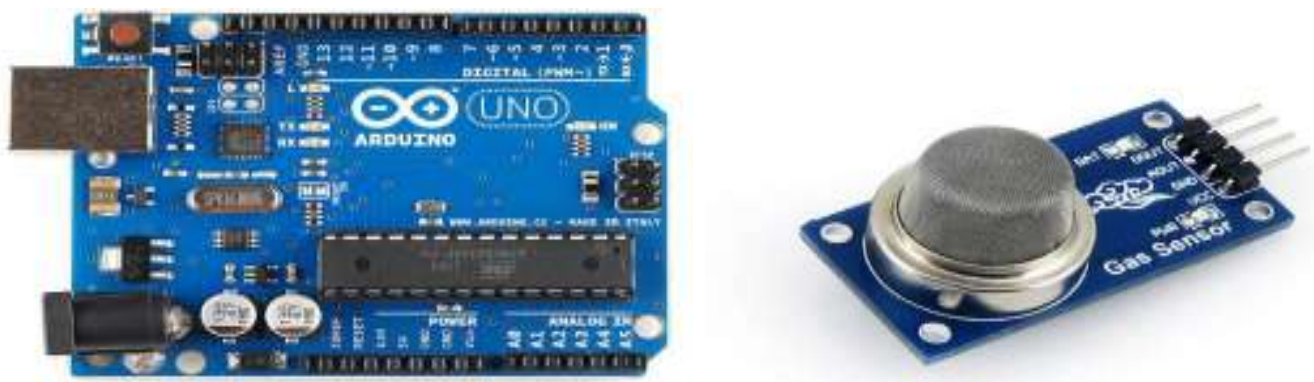

Figure1. Arduino UNO microcontroller and MQ-6 Sensor

\subsection{MQ-6 Smoke and Gas Sensor}

The MQ series of gas sensors use a small heater inside with an electro-chemical sensor shown in figure 1 . They are sensitive for a range of gasses and are used indoors at room temperature. The output is an analog signal and can be read with an analog input of a PIC microcontroller. The MQ-6 Gas Sensor module is useful for gas leakage detecting in home and industry. It is highly sensitive in the detection of the presence LPG, butane, propane, methane, alcohol, hydrogen and smoke. Some modules have a built-in variable resistor to adjust the sensitivity of the sensor. It was used in this research work for the detection of LPG and smoke in the building. The resistance of the sensor is different depending on the type of the gas. The smoke sensor has a builtin potentiometer that allows you to adjust the sensor sensitivity according to how accurate you want to detect gas [5, 7]. The coding for smoke detection is as follows:

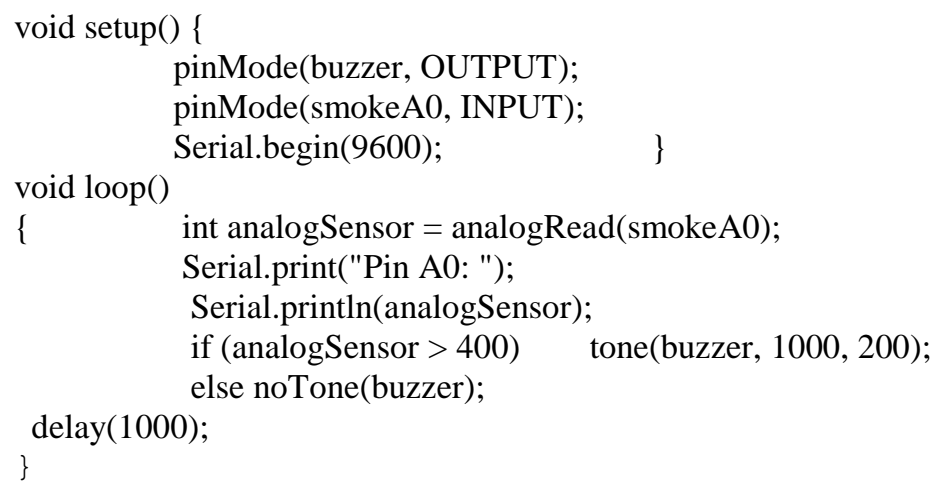

\subsection{Temperature and Humidity Sensor}

Humidity is a very important feature in detecting a fire. In case fire the air will be dry thus decreasing the humidity. This decrease in humidity can give us indication of forest fire. The DHT-11 sensor can be used to detect humidity in the range of 20$90 \%$ RH with the accuracy of $\pm 5 \%$ RH. DHT-11 uses resistive type humidity measurement component. The DHT11 and DHT22 sensors are fairly easy to connect. They have four pins: The DHT11 sensors are fairly easy to connect. They have four pins: VCC, Data, NC and Ground [5, 6, 7]. In figure 2, DH-11 sensor, Buzzer, GSM modem and LCD is displayed.

VCC pin supplies power for the sensor. Although supply voltage ranges from $3.3 \mathrm{~V}$ to $5.5 \mathrm{~V}, 5 \mathrm{~V}$ supply is recommended. In case of $5 \mathrm{~V}$ power supply, you can keep the sensor as long as 20 meters. However, with $3.3 \mathrm{~V}$ supply voltage, cable length shall not be greater than 1 meter. Data pin is used to communication between the sensor and the microcontroller. The casing is in two parts so to get inside it is just a matter of getting a sharp knife and splitting the case apart. Inside the case, on the sensing side, there is a humidity sensing component along with a NTC temperature sensor (or thermistor). Humidity sensing component is used, of course to measure humidity, which has two electrodes with moisture holding substrate (usually a salt or conductive plastic polymer) sandwiched between them. Higher relative humidity decreases the resistance between the electrodes, while lower relative humidity increases the resistance between the electrodes. In the the Arduino IDE, enter and will print the temperature and relative humidity values on the LCD display.

void $\operatorname{setup}()$

\{

void loop ()

pinMode(buzzer, OUTPUT);

Serial.begin $(9600)$

\{ int readData $=$ DHT.read11(dataPin $) ; / /$ DHT11 
float $\mathrm{t}=$ DHT.temperature; // Gets the values of the temperature

float $\mathrm{h}=$ DHT.humidity; // Gets the values of the humidity

Serial.print("Temperature = ", t," ");

Serial.print((char)176);//shows degrees character

Serial.print("C | ");

if (dataPin > 45)

tone(buzzer, 1000, 200);

else noTone(buzzer);

Serial.print $((\mathrm{t} * 9.0) / 5.0+32.0$, , “ $) ; / /$ print the temperature in Fahrenheit

Serial.print((char)176);//shows degrees character

Serial.println("F ");

Serial.print("Humidity = ", h, “ \% ”);

delay(1000); // Delays 2 secods
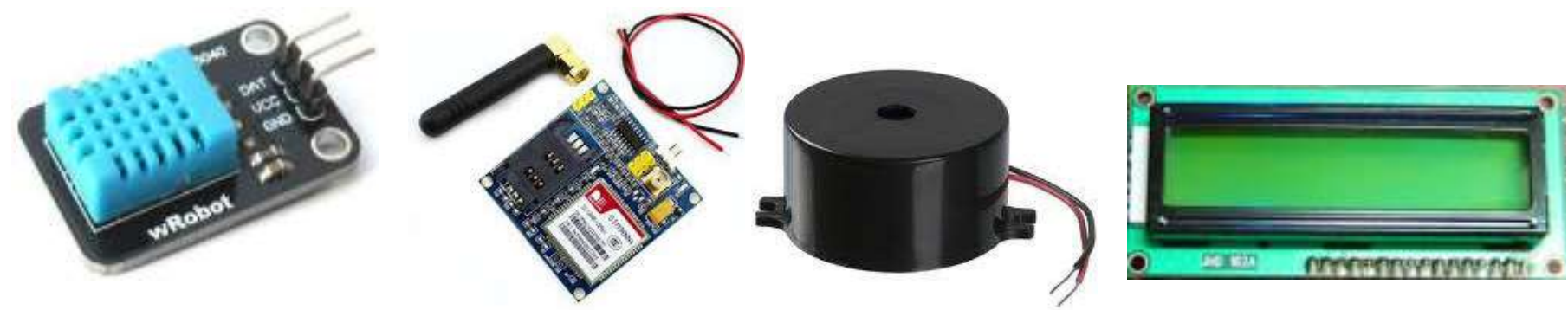

Figure2. DH-11 sensor, Buzzer, GSM modem (Sim900), Liquid crystal display unit (LCD)

\subsection{GSM Module}

This is a GSM/GPRS-compatible Quad-band cell phone, which works on a frequency of $850 / 900 / 1800 / 1900 \mathrm{MHz}$ and which can be used not only to access the Internet, but also for oral communication (provided that it is connected to a microphone and a small loud speaker) and for SMSs. The module is managed by an AMR926EJ-S processor, which controls phone communication, data communication (through an integrated TCP/IP stack), and (through an UART and a TTL serial interface) the communication with the circuit interfaced with the cell phone itself. The processor is also in charge of a SIM card ( 3 or $1,8 \mathrm{~V})$ which needs to be attached to the outer wall of the module. In addition, the GSM modem (Sim900) device integrates an analog interface, an A/D converter, an RTC, an SPI bus, an IC, and a PWM module [3, 4].

\subsection{Liquid Crystal Display Unit (LCD)}

This unit consists of a $16 \times 2$ Character LCD. The liquid crystal display is connected through a variable resistor; the variable resistor $(10 \mathrm{k} \Omega)$ is used to adjust the brightness of the LCD. The LCD displays the status of the system when gas detected or when a flame is detected through the various sensors installed the system. The following program will print the temperature and relative humidity values on the $16 \times 2$ character LCD [8].

LiquidCrystal lcd(12, 11, 5, 4, 3, 2); // Creates an LCD object. Parameters: (rs, enable, d4, d5, d6, d7)

dht DHT;

bool showcelciusorfarenheit $=$ false;

void $\operatorname{setup}()$

\{ lcd.begin(16,2); \}

void loop()

\{ int readData $=$ DHT.read11(dataPin);

float $\mathrm{t}=$ DHT.temperature;

float $\mathrm{h}=$ DHT .humidity;

lcd.setCursor $(0,0)$;

lcd.print("Temp.: ");

if(showcelciusorfarenheit) $\{\quad$ lcd.print $(\mathrm{t})$;

lcd.print((char)223);//shows degrees character

lcd.print("C");

showcelciusorfarenheit $=$ false; $\quad\}$

else $\{\quad$ lcd.print $((\mathrm{t} * 9.0) / 5.0+32.0)$;

lcd.print((char)223);//shows degrees character

lcd.print("F");

showcelciusorfarenheit = true; $\quad\}$

lcd.setCursor $(0,1)$;

lcd.print("Humi.: "); 
lcd.print(h);

lcd.print(" \%");

delay(2000);

\}

\subsection{Buzzer}

A buzzer is a mechanical, electromechanical, magnetic, electromagnetic, electro-acoustic or piezoelectric audio signaling device. A piezo-electric buzzer can be driven by an oscillating electronic circuit or other audio signal source. A click, beep or ring can indicate that a button has been pressed. It consists of a number of switches or sensors connected to a control unit that determines if and which button was pushed or a preset time has lapsed. It usually illuminates a light on the appropriate button or control panel, and sounds a warning in the form of a continuous or intermittent buzzing or beeping sound [8].

\section{FIRE DETECTION AND ALARM SYSTEMS}

Fire alarm systems include: Conventional fire alarm system, Addressable fire alarm system, Analogue addressable fire alarm system, and Wireless fire alarm system. Wireless fire alarm systems are an effective alternative to traditional wired fire alarm systems for all applications. It is a simple concept, which provides many unique benefits and is a full analogue addressable fire detection system without the need for cable. These systems can provide several main functions. First they provide a means to identify a developing fire based on smoke and gas through automatic methods and second, they alert building occupants to a fire condition. Another common function is the transmission of an alarm notification signal to the fire department or other emergency response organization. They may also shut down electrical, air handling equipment or special process operations, and they may be used to initiate automatic suppression systems. A fire sensor system based on the simultaneous detection $\mathrm{CO}, \mathrm{CO} 2$, and smoke concentrations, is demonstrated [6]. A fire detector is usually implemented as a smoke sensor due to its early fire detection capability, fast response time and relatively low cost.

The installed Arduino device which was programmed with Android Studio takes received gas, smoke, the temperature, and humidity signals from the sensors. The sensor is connected to the input of the arduino with the help of connecting cables or jumper cables. Further the circuit goes towards output where the buzzer is connected. If we differ the delay value of the buzzer then we get a variation in the buzzer sound. This can be applicable to detect various gases. Arduino is specially used in this design as it is easy to use in the circuit and the program upload is also very simple. By using Arduino Integrated Development Environment (IDE), MQ2 sensor Connect Arduino microcontroller to the computer. Then connect the VCC pin of your module to the to the $5 \mathrm{~V}$ pin of Arduino and connect the GND pin of your module to the GND pin of your Arduino. Finally, connect the Output pin of your module to the A0 pin of Arduino. The LCD shows the status of the system when there is a presence of gas or smoke which may lead to fire outbreak in the environment.

\subsection{Hardware Design}

In this system, a fire and smoke detection system is designed and developed using arduino controller. The arduino controller act as a main controller of system, Temperature and humidity sensor is used to detect rise in temperature and smoke sensor is used to detect the smoke. Buzzer act as an alarm and Wifi module is used to create the wireless communication between android phone and controller. Also the controller will send command to virtual terminal of android phone about the fire and smoke detection through the GSM module. General Fire detection and alarm system and Block diagram are shown in figure 3 and 4.

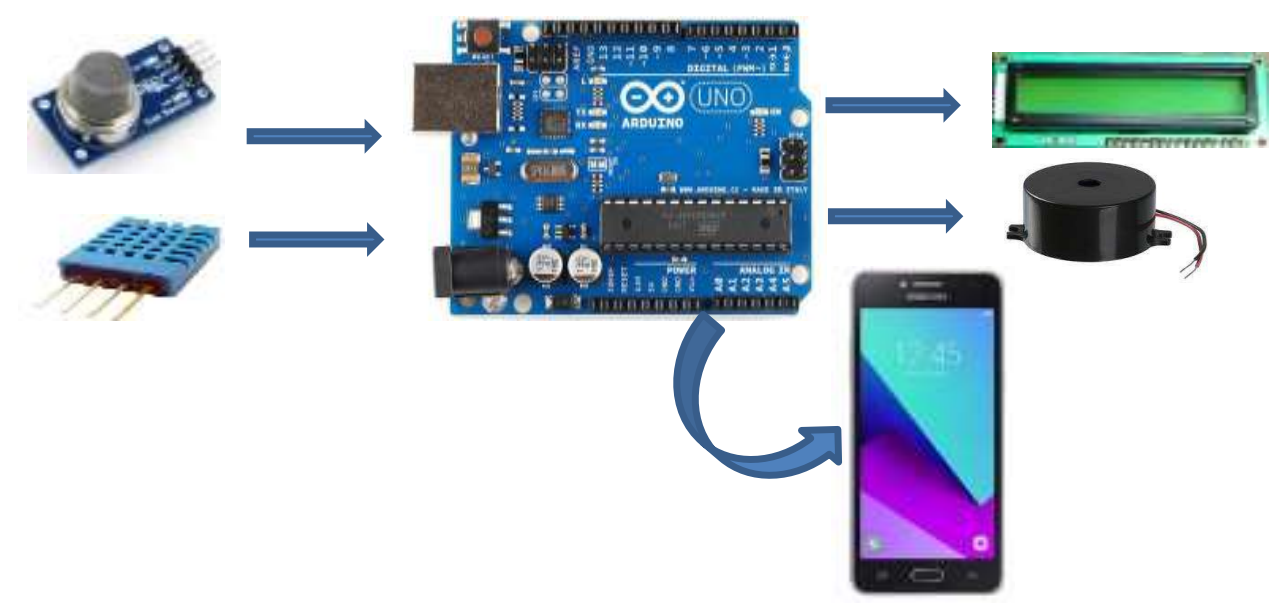

Figure3. Fire Detection and Alarm Systems

\subsection{Software Design}


Arduino fire alarm system is an important system for industrial purposes as well as for household purposes. Whenever it detects fire or smoke then it instantly alerts the user about the fire through the GSM module. Software design is as shown in figure 5 .

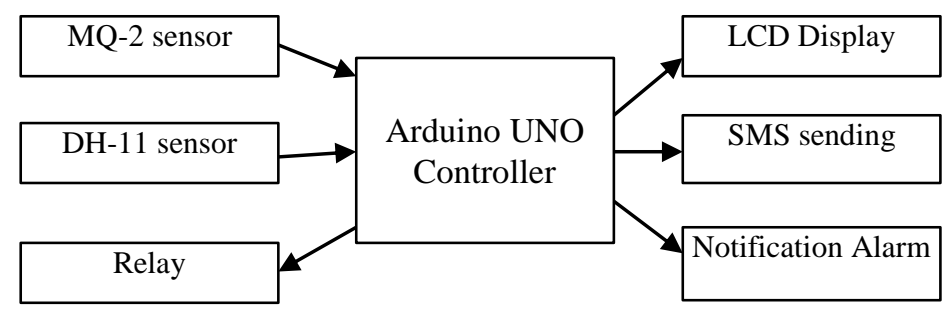

Figure4. Block Diagram

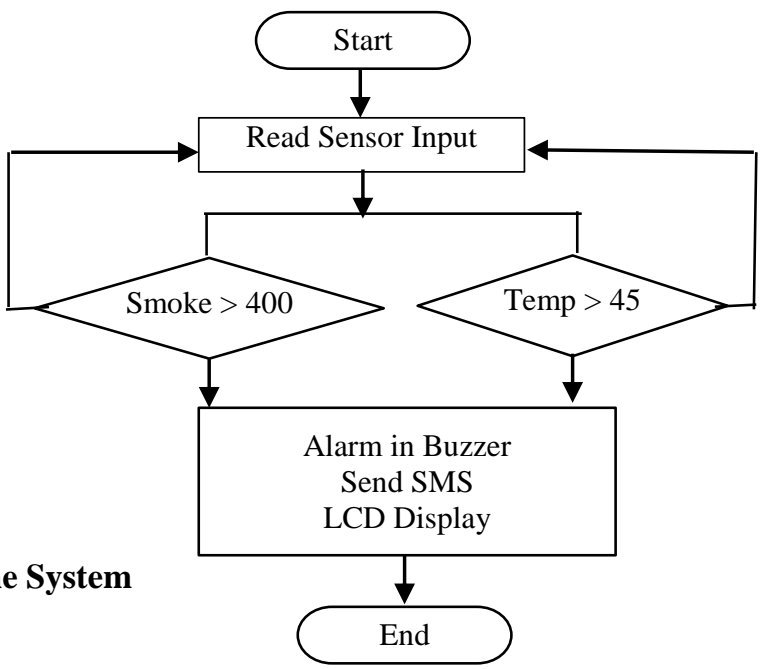

\section{IMPLEMENTATION RESULT}

Figure5. Flow chat of the System

The hardware of this case consists of Gas sensor, temperature and humidity sensor, Arduino microcontroller, GSM SIM- 900A that is connected with Arduino through an relay module to control it. A fire alarm system is number of devices working together to detect and warn people through visual and audio appliances when smoke, fire, carbon monoxide or other emergencies are present. Fire and smoke that spread within a building can be affected by various factors such as the geometry, dimension, layout and usage of the building. If a detector detects smoke or heat, or someone operates a break glass unit, then alarm sounders operate to warn others in the building that there may be a fire and to abandon.

\section{CONCLUSION}

This paper presents the design and implementation of a cost-effective and reliable automated GSM based fire alarm system. Fire detectors use various sensor, generally a smoke sensor and temperature and humidity sensor. The sensor input data is connected with Arduino controller. LCD display, Buzzer and GSM module also is connected with Arduino for output result. Buzzer is notify for fire alarm and LCD is displayed the fire detection status. GSM module can be informed to specific user to know or prevent their home, office or building. This system can be applied in residential places, offices and hotels. With this system safety is assured. The system can perform different parameter measurements for early detection of building fires. There should be a minimum of two or three smoke and detectors in your home. You should install a smoke and detector on each floor of a house. Always have a smoke and detector and fire alarm system in your home for your own safety. The advantages of the system can help in early reaction, saving lives and property. It can also protects us and our residence.

\section{REFERENCES}

1. Official Arduino BT website: http://www.arduino.cc/en/Guide/ArduinoBT

2. John Boxall, "Arduino Workshop", 2013.

3. Karwan MUHEDEN, Ebubekir ERDEM, Sercan VANÇ $\square$ N, Design and Implementation of the Mobile Fire Alarm System Using Wireless Sensor Networks, CINTI 2016, 17th IEEE International Symposium on Computational Intelligence and Informatics • 17-19 November, 2016 • Budapest, Hungary

4. N N Mahzan, N I M Enzai, N M Zin and K S S K M Noh, Design of an Arduino-based home fire alarm system with GSM Module, 1st International Conference on Green and Sustainable Computing (ICoGeS) 2017, IOP Conf. Series: Journal of Physics: Conf. Series 1019 (2018) 012079 doi :10.1088/1742-6596/1019/1/012079

5. P.J. Vivek, G. Raju, S. Akarsh, "Forest Fire Detection System", International Journal of Innovative Research in Science, Engineering and Technology, ISSN: 2319-8753, Vol 3, Issue 6, June 2014

6. Prof. Parag Naik, Pranay Dhopte, Rajat Wanode, Roheet Kantode, Saurabh Nagre, Gas Sensor Using Arduino UNO \& MQ2 Sensor, International Journal of Advanced Research in Computer and Communication Engineering ISO 3297:2007 Certified Vol. 7, Issue 3, March 2018 
International Journal of Advances in Scientific Research and Engineering (ijasre), Vol 6 (4), April -2020

7. R.O.Okeke, M.Ehikhamenle, Design And Simulation Of Gas And Fire Detector And Alarm System With Water Sprinkle, International Journal of Engineering Research and General Science Volume 5, Issue 1, January-February, 2017 ISSN 2091-2730

8. T. L. Floyd, Ninth edition, “Digital Fundamentals”, New Jersey, 2006. 